\title{
Achieving SDG 3.8.2: Financial Protection Against Catastrophic Health Expenditure in Malaysia
}

\author{
Surianti Sukeri ( $\nabla$ surianti@usm.my) \\ Department of Community Medicine, School of Medical Sciences, UniversitiSains Malaysia, 16150 Kota Bharu, Kelantan, Malaysia \\ https://orcid.org/0000-0003-0974-7074 \\ Muaz Sayuti \\ Faculty of Medicine and Health Sciences, Universiti Malaysia Sarawak, 94300 Kota Samarahan, Sarawak.
}

\section{Research}

Keywords: Sustainable Development Goals, catastrophic health expenditure, financial protection, universal health coverage

Posted Date: August 13th, 2020

DOI: https://doi.org/10.21203/rs.3.rs-54824/v1

License: (c) (i) This work is licensed under a Creative Commons Attribution 4.0 International License. Read Full License 


\section{Abstract}

Background: The Sustainable Development Goal (SDG) 3.8.2 is one of the two indicators to monitor a country's progress towards universal health coverage. It concerns the financial protection against catastrophic spending on health based on the budget share approach. The purpose of this study is twofold: 1) to measure SDG 3.8.2 on the proportion of households with catastrophic health expenditure (CHE), and 2) to determine households at risk of $\mathrm{CHE}$

Methods: A cross-sectional study was conducted using secondary data from the 2015/2016 Household Expenditure Survey. The inclusion criterion was Malaysian households with some health spending in the past 12 months before the date of the survey. The World Health Organization method of calculating CHE was applied in the calculation, and a threshold of $10 \%$ out-of-pocket health spending from total household expenditures was used to determine $\mathrm{CHE}$. Data were analysed descriptively, and multiple logistic regression was used to determine factors associated with $\mathrm{CHE}$.

Results: A total of 13015 households were involved in the study. The proportion of CHE was $2.8 \%$. Four associated factors that were statistically significant were female-headed household (Adjusted OR 1.6; CI 1.25, 2.03; p-value <0.001), household that lived in rural area (Adjusted OR 1.29; $95 \% \mathrm{Cl} 1.04,1.61$; p-value $=0.022$ ), small household size (Adjusted OR 2.4; 95\% Cl 1.81, 3.18; $\mathrm{p}$-value $<0.001$ ) and head of household aged below 60 years old (Adjusted OR2.34; 95\% Cl 1.81, 3.18; p-value <0.001).

Conclusions: The low proportion of CHE revealed that Malaysia is on the right track towards achieving SDG 3.8 on universal health coverage status by 2030. However there is an increasing trend in the proportion of CHE. Households at risk of CHE require financial protection to afford healthcare and safety net measures to prevent from spiralling further into the vicious cycle of illness and poverty.

\section{Background}

In September 2015, the United Nations General Assembly adopted 17 Sustainable Development Goals (SDG) as a universal call to end poverty, protect the planet and ensure that all people enjoy peace and prosperity. The SDG 3 bid to ensure healthy lives and promote well-being for all, while SDG 3.8 focuses on achieving universal health coverage that includes financial risk protection, access to quality essential healthcare services and access to safe, effective, quality and affordable essential medicines and vaccines for all. Target 3.8 has two indicators; 3.8 .1 on coverage of essential health services and 3.8.2 on the proportion of a country's population with catastrophic spending on health $(1,2)$.

This study aims to measure the SDG target 3.8.2 as it is key to achieving the universal health coverage status by 2030 , which meant all individuals and communities should have access to equitable and quality essential health services without suffering financial hardship. Financial hardship is measured through catastrophic health expenditures (CHE); which occurs when out-of-pocket spending for health exceed a household's ability-topay, thus forcing a household to divert spending away from essential items such as food, shelter and clothing until the spending on these items is reduced below the level indicated by the poverty line (1). It was estimated that half of the world population have limited coverage of vital health services. In 2010, among those who have access to health, 11.7\% (808 million people) of the world population suffered from CHE (2).

There are many approaches to measuring CHE. The most common is the World Bank and World Health Organization (WHO) budget share method which defines $\mathrm{CHE}$ as the proportion of the population with large household expenditure (10\% and $25 \%$ ) on health as a share of total household expenditure or income (1). The $10 \%$ total household expenditure threshold was selected as it is the preferred indicator used by the World Bank and the WHO in their 2017 Global Monitoring Report on universal health coverage. The OOP is defined as payments made by households at the point of receiving any health services. Out-of-pocket payments could be financed out of a household's income, savings, or borrowing. They exclude any reimbursement by a third party, such as an employer or individual private insurance. Data on household OOP health spending can be collected from various sources such as the national Household Expenditure Survey (HES), Household Income and Basic Amenities, the Malaysia National Health Account and the National Health and Morbidity Survey (3-5).

Data on OOP health spending alone cannot determine whether a household is suffering from financial hardship. As such, high OOP spending on health by wealthy households are not considered catastrophic, as there is more expendable income to spend. Poorer households, on the other hand, are more vulnerable to sudden, unbudgeted OOP health spending in the occurrence of sudden health event. They are more likely to prioritise household income on necessities; thus OOP health payments incurred may deter the poor from seeking care (6).

In 2010, 808 million people incurred CHE at the $10 \%$ threshold of total household consumption or income, and 179 million suffered such payments at the $25 \%$ threshold (7). Between 2000 to 2010 , the region with the fastest increase in a population facing $\mathrm{CHE}$ at $10 \%$ threshold is Africa followed by Asia (1). The increasing trend of CHE which occurred around the world is alarming. Since the year 2000, a rising trend in the proportion of CHE was noted globally from $9.7 \%$ to $11.4 \%$ in 2009 and $11.7 \%$ in 2010 . Countries from Latin America and the Caribbean had the highest proportion of CHE (14.8\%) in 2010, followed by Asia (12.8\%). Countries from Oceania and North America had the lowest proportion of CHE compared to other countries in 2010 (3.9\% and $4.6 \%$ respectively) (7).

A study by Van Doorslaer et al.,(8) using data obtained from national expenditure survey of 11 low to middle-income countries showed that household in countries like China, Vietnam, Bangladesh and Nepal had to spend more than $60 \%$ of their health expenditure from 00P. This result in 
a marked increase in poverty estimation from additional 1\%-2\% of the population in Vietnam to 3\%-8\% population in Bangladesh. In Nigeria, a study using Harmonized Nigeria Living Standard Survey of $2009 / 2010$ showed that $16.4 \%$ of households in Nigeria suffered from CHE at $10 \%$ expenditure threshold. The same study also showed a lower proportion of CHE (13.7\%) in Nigeria when using $40 \%$ of total non-food expenditure. Other African countries experienced a higher proportion of $\mathrm{CHE}$; for instance, $22.8 \%$ in Uganda and $22.4 \%$ in Egypt with $10 \%$ threshold of total health expenditure (9). In Malaysia, an unpublished data reported that only $1.44 \%$ of households experienced $\mathrm{CHE}$ at $10 \%$ threshold (10). While the WHO Regional Office for the Western Pacific reported zero per cent CHE at 25\% threshold (11). However, these findings were based on the $2004 / 2005$ HES, and since then, no newer study was done on the measurement of CHE and its associated factors at a national scale. Moreover, due to the nature of these reports, there was an incomplete explanation of the methodology as to how these numbers were derived.

Data from nationally representative household surveys containing information on OOP health spending and household expenditures can be used to measure the SDG 3.8.2 on the incidence of CHE (1). It is recommended as a methodologically sound measure of the financial burden of healthcare costs on household that will assist health policy-makers to better comprehend the effectiveness of different policy instruments, and support evidence-based policy-making (12). In Malaysia, the data on OOP health spending is available from the Household Expenditure Survey (HES), conducted by the Department of Statistic Malaysia. This survey provides statistics and data about general household consumption, including those on health. Findings from this survey were used by the government agencies in planning, formulating and monitoring the national development plan. This five-yearly survey was carried out by probability sampling that represented all households in Malaysia and was first conducted in 1957. The purpose of this survey was to collect information on households and the pattern of consumption expenditure on a variety of goods and services. This information was used to update the consumer price index which is a measure of the average rate of change in prices of a fixed basket of goods and services which represent the expenditure pattern of all households in Malaysia. The data are available for interested parties such as economists, academicians and others for research purposes (13). The $2020 \mathrm{HES}$ is currently ongoing. As such, the latest completed survey data available to the public is the $2015 / 2016$ HES and to date, it has not been utilised to measure CHE.

The HES collects household data on OOP spending on health expenditure, but it alone does not reflect the actual financial hardship resulting from care-seeking events. Therefore, a better indicator is the measurement of CHE. The HES data is currently underutilised; it is not being used to measure $\mathrm{CHE}$. Those who experience $\mathrm{CHE}$ are at risk of poverty thus affecting the affordability to purchase food and other necessities. On the other hand, those who cannot afford may have to forgo treatment, resulting in a barrier to care. Catastrophic health expenditure will also affect universal health coverage status. It is one of the key indicators used in monitoring target 3.8.2 of the Sustainable Development Goals. Therefore, the findings of the study will help to partly answer whether Malaysia has achieved the universal health coverage status. This study is also intended to fill the knowledge gap and for better understanding of the associated factors of CHE in Malaysia. By providing evidence-based information, it may be used to develop a health financing policy and strategy on the safety net to reduce CHE in Malaysia.

\section{Methods}

\section{Study setting}

Malaysia is an upper-middle-income country located in South-East Asia. With a population of 32.6 million, the total expenditure on health as a percentage of GDP in 2017 was 4.24\% (5). Following the Beveridge model, health financing in Malaysia is primarily from general taxation; there is no social or national health insurance. Public health care is provided at a highly subsidised rate. Maternal and child care, infectious diseases, are provided free for all Malaysians. Government employees, the disabled and disadvantaged are exempted from paying all treatment-related charges. Meanwhile, private health care contributes $48.9 \%$ of the total expenditure on health and is financed on a non-subsidized fee through out-of-pocket or voluntary private health insurance (14).

\section{Study design and study sample}

The study design was a cross-sectional study that used secondary data from 2015/2016 HES. We included all households recruited in $2015 / 2016$ HES with some health spending (> Malaysian Ringgit; MYR 0). The sample size was calculated using single and two proportion formula via the PS Software. The highest sample size required for the study was 9156 households. However, no sampling method was applied; all households which fulfilled the study criterion were included in the study.

\section{Study data}

The study data used was from the 2015/2016 HES data.

\section{Data collection}

The 2015/2016 HES data was provided by its custodian; Data Mikro, School of Mathematical Sciences, Universiti Sains Malaysia. Permission to use the data was obtained prior to the data extraction. The raw data was emailed to the researcher in separate Microsoft Excel files due to its size in February 2019. Data extraction was performed using a proforma. The data acquired include: 
- Households' characteristics: age, gender, ethnicity, household size, household members' age, household income, location, education, health insurance status and marital status.

- All out-of-pocket spending on healthcare and all household expenditures for consumption (personal goods and services including tax, food and house rental fees) and non-consumption items (social security, charity, income tax, summons and alimonies payment)

\section{Data analysis}

Data were screened and imputed in Microsoft Excel spreadsheets. It was then combined and exported to IBM SPSS version 24 software for analysis. Descriptive statistics were used to summarise the socio-demographic characteristics of households. Numerical data were presented as mean (SD) or median (IQR) based on their normality distribution. Categorical data as presented as frequency (percentage). Following the WHO approach, CHE is defined as OOP health expenditure exceeding $10 \%$ of total household expenditure.

$C H E=\left(\frac{O O P}{H H \exp } x 100\right)>10 \%$

OOP: Refers to direct payments made by individuals to health care providers at the time of service use

\section{$\mathrm{HH} \exp$}

Total household expenditure on consumption (personal goods and services including tax, food and house rental fees) and non-consumption items (social security, charity, income tax, summons and alimonies payment)

The dependent variable was CHE (yes/no), whilst independent variables were age of head household, ethnic group, income classification, household size, level of education, location, gender head of household, health insurance status and marital status.

Simple and multiple logistic regression was applied to determine the associated factors. To obtain the preliminary final model, variables were selected using Forward Likelihood selection and Backward Likelihood elimination methods. Multicollinearity and interaction between significance variable were checked using correlation table, standard error and variance inflation factors. All possible two-way interaction between independent variables was checked. Subsequently, the fitness of the model was checked using the Hosmer Lemeshow test, classification table and receiver operating characteristic (ROC) curve. The final model of multiple logistic regression will be presented as adjusted OR with $95 \%$ confident interval, Wald statistic and corresponding $\mathrm{p}$ value. Variable with $\mathrm{p}$ value less than 0.05 is considered to be a significant associated factor for $\mathrm{CHE}$.

\section{Results}

A total of 13015 households from the $2015 / 2016$ HES were included in this study. Around $10.5 \%$ of households were excluded from the study as they did not report any health expenditure in the survey. The mean age of the household heads was 47 years old (SD 13.57) and the mean household size was 4.14 (SD 2.05). Majority of the head of households were aged below 60 years old (82\%), male (83\%), native Bumiputera $(66.6 \%)$, still married $(77.4 \%)$, lived in urban areas $(69.3 \%)$ and had low education level $(75.8 \%)$.

The OOP data were skewed; means were presented together with medians to enable comparison with national averages in discussing the study findings. The numbers may seem insignificant due to the conversion of Malaysian Ringgit (MYR to US dollars (conversion rate 1 MYR: 0.24 USD). From this study, the median monthly household income was USD1140.41 (IQR1139.87). Around 46\% came from low-income households, and only $6.2 \%$ of households purchased private health insurance. This study also found that the median monthly household expenditure was USD756.52 (IQR588.06) and the median monthly OOP health expenditure was USD5.84 (IQR22.16).

In Table 1, median OOP health expenditures between household size classification, gender and marital status were generally about the same. However, for households headed by individuals aged more than 60 years old, of Chinese ethnic, highly educated, resided in urban areas, of highincome group and purchased private health insurance, had relatively higher median OOP health spending than their counterparts. Chinese households spent the highest OOP health expenditure compared to other ethnics with a median of USD10.17 (IQR24.21). There was a considerable gap in the median OOP health expenditure between income groups. The wealthiest households spent the most on health with a median of USD13.79 (IQR38.67) compared to the lowest income group with a median of USD3.51 (IQR7.98) 
Table 1

Demographic characteristics and distribution of monthly out-of-pocket health expenditures (USD) $(\mathrm{N}=13015)$

\begin{tabular}{|c|c|c|c|}
\hline \multirow[t]{2}{*}{ Variable } & \multirow[t]{2}{*}{$\mathrm{n}(\%)$} & \multicolumn{2}{|c|}{ Monthly out-of-pocket health expenditures (USD) } \\
\hline & & Mean (SD) & Median (IQR) \\
\hline Age head of household & & $11.37(3.28)$ & \\
\hline$<60$ years & $10675(82.0)$ & $16.91(42.38)$ & $5.37(13.96)$ \\
\hline$\geq 60$ years & $2340(18.0)$ & $22.16(42.12)$ & $7.25(22.41)$ \\
\hline Household size & & $4.14(2.05)$ & \\
\hline \multicolumn{4}{|l|}{ Household members } \\
\hline 1 to 2 & 2977 (22.9) & $18.47(40.45)$ & $5.86(17.10)$ \\
\hline 3 to 4 & $5001(38.4)$ & $17.73(39.93)$ & $5.84(15.76)$ \\
\hline 5 and above & $5037(38.7)$ & $17.62(45.73)$ & $5.36(13.89)$ \\
\hline \multicolumn{4}{|l|}{ Gender } \\
\hline Male & $10823(83.2)$ & $17.86(43.92)$ & $5.64(14.96)$ \\
\hline Female & $2192(16.8)$ & $17.86(33.77)$ & $5.75(16.30)$ \\
\hline \multicolumn{4}{|l|}{ Ethnicity } \\
\hline Bumiputera & $8670(66.6)$ & 15.46 (31.03) & $4.83(12.79)$ \\
\hline Chinese & 2897 (22.3) & $26.06(52.92)$ & $10.17(24.21)$ \\
\hline Indian & $872(6.7)$ & $18.51(41.77)$ & $6.45(14.74)$ \\
\hline Others & $576(4.4)$ & 11.60 (68.09) & $3.02(5.75)$ \\
\hline \multicolumn{4}{|l|}{ Marital Status } \\
\hline Married & 10072 (77.4) & 18.21 (43.09) & $5.81(16.65)$ \\
\hline Not Married & 1716 (13.2) & 18.27 (47.29) & $5.56(14.44)$ \\
\hline Divorced & $1227(9.4)$ & $14.35(25.90)$ & $4.84(13.31)$ \\
\hline \multicolumn{4}{|l|}{ Location of residence } \\
\hline Urban & 9018 (69.3) & $19.67(46.42)$ & 6.55 (17.73) \\
\hline Rural & 3997 (30.7) & $13.76(31.03)$ & $4.03(10.03)$ \\
\hline \multicolumn{4}{|l|}{ Education Level } \\
\hline Low & $9870(75.8)$ & $15.26(31.37)$ & $5.03(12.73)$ \\
\hline High & 3145 (24.2) & $26.01(65.25)$ & $8.44(24.26)$ \\
\hline Income & & $1523.44(1453.10)$ & $1140.41(1139.87)$ \\
\hline \multicolumn{4}{|l|}{ Income Group } \\
\hline Low & $5952(45.7)$ & $9.98(19.91)$ & $3.51(7.98)$ \\
\hline Middle & 4910 (37.7) & 18.68 (32.03) & 7.25 (18.39) \\
\hline High & 2153 (16.5) & $37.74(82.80)$ & 13.79 (38.67) \\
\hline \multicolumn{4}{|c|}{ Purchased Private Health Insurance } \\
\hline No & $12208(93.8)$ & $17.60(42.59)$ & $5.55(14.93)$ \\
\hline Yes & $807(6.2)$ & $21.71(38.86)$ & $7.96(18.96)$ \\
\hline Household expenditure & & $911.20(688.71)$ & $756.52(588.06)$ \\
\hline OOP health expenditure & & $17.86(42.38)$ & $5.84(22.16)$ \\
\hline
\end{tabular}


In the current study, a threshold of 10\% OOP share of health expenditure was used to define CHE. However, proportions of CHE calculated based on various thresholds of expenditure and income were presented to enable comparison with other studies in the literature. From Table 2 it was observed that the proportion of CHE was higher if the household expenditure was used as the denominator. At $10 \%$ threshold of household expenditure, the proportion of $\mathrm{CHE}$ was $2.8 \%(95 \% \mathrm{Cl} 2.5,3.1)$ compared to only $1.5 \%(95 \% \mathrm{Cl} 1.3,1.7)$ if household income was used as the denominator. Regardless of the denominator used, higher threshold led to a lower proportion of $\mathrm{CHE}$. To demonstrate, when the $40 \%$ threshold was used, the proportions of $\mathrm{CHE}$ were reduced to $0.03 \%$ and $0.04 \%$ respectively.

Table 2

Proportion of $\mathrm{CHE}$ based on different indicators and thresholds $(n=13015)$

\begin{tabular}{|llll|}
\hline & \multicolumn{3}{c|}{ Proportion of CHE } \\
\hline Denominator & Threshold & $\mathrm{N}(\%)$ & $95 \% \mathrm{Cl}$ \\
\hline Expenditure & $5 \%$ & $1285(9.9)$ & $9.4,10.4$ \\
& $10 \%$ & $367(2.8)$ & $2.5,3.1$ \\
& $20 \%$ & $62(0.5)$ & $0.4,0.6$ \\
\hline Income & $40 \%$ & $5(0.04)$ & $0.01,0.07$ \\
& $5 \%$ & $722(5.5)$ & $5.2,5.9$ \\
& $10 \%$ & $190(1.5)$ & $1.3,1.7$ \\
& $20 \%$ & $38(0.3)$ & $0.2,0.4$ \\
& $40 \%$ & $4(0.03)$ & $0.00,0.06$ \\
\hline
\end{tabular}

\section{Factors associated with $\mathrm{CHE}$}

Multiple logistic regression analysis showed that gender and age of household head, household location and size were significantly associated with $\mathrm{CHE}$. There was no multicollinearity between the variables as evidenced by the low correlation between the variables in the correlation matrix, small standard error and the VIF is less than ten. All possible two-way interactions between the variables were checked, and no interaction was found. The model was proved to be fit as the Hosmer-Lemeshow was not significant with p-value 0.82 and the classification table showed $97.2 \%$. The area under the ROC was 68.8\% (95\% Cl 0.659, 0.717; p-value < 0.001) (Table 3).

A female-headed household had 1.6 times the odds to incur CHE compared to the male-headed household $(95 \% \mathrm{Cl} 1.25,2.03 ; \mathrm{p}$-value $<0.001)$ when adjusted with household location, size and age head of household. Households headed by individuals aged $<60$ years old were 2.34 times more likely to incur CHE compared to those aged $\geq 60$ years old $(95 \% \mathrm{Cl} 1.86,2.95$; $\mathrm{p}$-value $<0.001)$ when adjusted with gender, location, and household size. A household located in a rural area was 1.29 times more likely to develop CHE compared to a household that lived in an urban area $(95 \% \mathrm{Cl} 1.04,1.61$; $\mathrm{p}$-value $=0.022)$ when adjusted with gender, household size and age head of household. A household with 1 to 2 family members was 2.4 times more likely to suffer CHE compared to a household size of 5 and above $(95 \% \mathrm{Cl} 1.81,3.18$; p-value < 0.001$)$ when adjusted with gender, location and age head of household. 
Table 3

Association between socio-demographic and characteristic of household with CHE using Multiple Logistic Regression ( $n=13015)$

\begin{tabular}{|c|c|c|c|c|}
\hline Head of household/ household characteristics & $\beta$ & $\begin{array}{l}\text { Adjusted OR } \\
(95 \% \mathrm{Cl})\end{array}$ & Wald Statistic (df) & p-value \\
\hline \multicolumn{5}{|l|}{ Age } \\
\hline$\geq 60$ years & 0.850 & 1 & $51.702(1)$ & $<0.001$ \\
\hline$<60$ years & & $2.34(1.86,2.95)$ & & \\
\hline \multicolumn{5}{|l|}{ Gender } \\
\hline Male & 0.467 & 1 & $14.435(1)$ & $<0.001$ \\
\hline Female & & $1.60(1.25,2.03)$ & & \\
\hline \multicolumn{5}{|l|}{ Location } \\
\hline Urban & 0.255 & 1 & $5.234(1)$ & 0.022 \\
\hline Rural & & $1.29(1.04,1.61)$ & & \\
\hline \multicolumn{5}{|l|}{ Household Size } \\
\hline 5 and above & 0.874 & 1 & $36.737(1)$ & $<0.001$ \\
\hline 1 to 2 & 0.114 & $2.40(1.81,3.18)$ & $0.598(1)$ & 0.439 \\
\hline 3 to 4 & & $1.12(0.84,1.50)$ & & \\
\hline
\end{tabular}

Forward LR and Backward LR methods were applied

No multicollinearity and no interaction

Hosmer-Lemeshow test, p-value 0.82

Classification table $97.2 \%$

The area under ROC curve $68.8 \%$

\section{Discussion}

Based on the 2015/2016 HES, this study revealed that the SDG 3.8.2 indicator on the proportion of CHE among Malaysian households is 2.8\%. The proportion of CHE in this study was higher than those obtained from the $2004 / 2005$ HES of $1.44 \%$ (10). It is also higher compared to the proportion of CHE calculated using the $1998-1999$ HES of $2.01 \%$ ( $10 \%$ threshold) and $6.62 \%$ (5\% threshold) (8). The increase in the CHE proportion over the years was assumed to be associated with inflation and the rapid expansion of private healthcare in Malaysia, thus increasing the OOP health expenditure. As theorised by Van Doorslaer et al., (15) the trend of CHE is affected by OOP health expenditures. The Malaysia National Health Accounts reported an increase in the OOP health expenditures from USD1491 million in 2004 to USD4035 million in 2016 (5). However, the proportion of $\mathrm{CHE}$ in this study was far lower than the global estimation of $11.7 \%$ in the 2010 World Bank report. The low proportion of $\mathrm{CHE}$ may be due to the tax-based health financing system in Malaysia, which provides subsidised healthcare in all public healthcare institutions (5). Extremely low proportion (0.00\%-2.99\%) of CHE were observed in countries with near-identical health financing models such as the United Kingdom, Italy, New Zealand, Denmark, Sweden, Brunei and Saudi Arabia (1). Our study findings reaffirm the fact that increasing the share of total health expenditure that is prepaid through taxes will lead to reduced catastrophic payment incidence (7). On the other hand, our findings may be an underestimation of the true number of CHE. According to Cylus et al., the budget share method overestimated financial hardship among rich households and underestimated hardship among poor households (16). However, this finding was generated among the European population, which may not be relevant to the local context. A low incidence of CHE may also indicate people are not getting (and not paying for) needed care (7) or the HES sampling of healthier populations who may not require regular medical care. Previous studies in Malaysia found the proportion of CHE was observed to be as high as $47.8 \%$ among households affected by colorectal cancer (17), 33.0\% for acute gastroenteritis requiring hospitalization (6) and $16.0 \%$ among patients with ischaemic heart diseases (18).

Discussing OOP health spending in the 2015/2016 HES is crucial. High OOP expenditures was often misjudged as an undesirable outcome. The Malaysia National Health Accounts reported 38\% of healthcare expenditure in Malaysia is paid OOP; however, if one were to understand the concept of $\mathrm{CHE}$, high OOP does not necessarily translate into catastrophic spending. For example, we discovered that households headed by 
individuals $<60$ years old was 2.34 times more likely to suffer $\mathrm{CHE}$, whereas the median OOP health spending among older household was in fact, higher. Furthermore, these older households were smaller in size ( $79.7 \%$ have $<5$ household members), yet they spent more on their healthcare expenditures. This may be due to these older households requiring more money for treatment and rehabilitation of chronic diseases which are more prevalent among the elderly. A similar observation was found in a study among Malaysians which reported higher mean expenditure on health among those aged $>50$ years old compared to those < 35 years old (USD15.98 vs USD9.25). Young Malaysians were found to spend a more significant portion of their total spending on holidays, clothing and entertainment which resulted in a smaller balance of their spending on health (19).

Between ethnic groups, it was discovered that Chinese households spent more on healthcare. In contrast, the National Health and Morbidity Survey 2015 reported that Malay households spent the highest OOP on health (USD 125.52; 95\% Cl, RMO - USD294.57). According to the said report, Chinese households were the least to utilise both government inpatient (43.7\%; 95\% Cl, 29.4-59.0) and outpatient care (52.3\%; 95\% $\mathrm{Cl}$, 43.3-61.1) mainly because of their private health insurance coverage (49.5\%; $95 \% \mathrm{Cl}, 46.4-52.6)$ (4).

The OOP health spending among urban households was higher compared to rural households in this present study. This finding was in line with the 2015 National Health and Morbidity Survey report which showed markedly higher OOP health spending among the urban populations. This may be due to the high utilisation of public health facilities in the rural area. However, this finding was also due to the differences in income and higher spending power among the urbanites. This study also found that $44.3 \%$ of the rural households were from the low-income group compared with only $36.8 \%$ in urban populations. Furthermore, higher concentrations of private healthcare facilities in urban areas due to the high demand also lead to higher OOP health spending among the urbanites. This is also evidenced by the National Health and Morbidity Survey 2015 which reported higher utilisation of private healthcare facilities among urban populations $(30.4 \% ; 95 \% \mathrm{Cl}, 28.2,32.7)(4)$.

Highly educated households were found to have more OOP health expenditure, and the same finding was also reported in the National Health and Morbidity Survey 2015. The difference in health spending was a direct reflection of higher income among most households with high education status. The OOP health spending among married and unmarried head of households was approximately the same, however, among divorced or widowed head of household it was found to be slightly lower. From the National Health and Morbidity Survey 2015, high 00P health spending was recording among married households. A recent study showed that married household usually has more frequent visits to healthcare facilities compared to unmarried households (20). As for widowed and divorced household, the low OOP health spending can be due to the fewer number of breadwinners in the household, which contributed to the low income and expenditure.

Households categorised in the high income group in this study were spending more than the others. This finding is identical to other studies which showed higher OOP health spending among wealthier households (21-23). Such a common scenario is due to the high spending power within the wealthier households, which is the main reason OOP spending is concentrated among the more affluent population. These high OOP spending will not incur $\mathrm{CHE}$ since their total spending was in concurrence with their income. Most of the affluent households utilises private health facilities compared to the government health facilities, which led to an increase in the OOP expenditure on health (21). Notably, households with health insurance had higher OOP spending compared to households without health insurance. Further analysis showed that $46.7 \%$ of households with no health insurance were from the low income group which explained the low OOP health spending among these households.

The multivariable analysis identified four factors that were significantly associated with CHE in this study, mainly head of household age and gender, location and household size. Female-led households were more likely to suffer from CHE compared to their male counterparts. Even though the OOP of health expenditure was the same between male and female-led households, the median monthly expenditure of female (USD639.16; IQR 553.73) was less than male (USD774.48; IQR 589.43). The low expenditure among the female-led households may be due to the lower income received, compared to male-led households. A previous study done in Malaysia showed that a $1 \%$ increase in income would increase $0.5 \%$ of total expenditure (19). This finding was also evidenced in the Salaries and Wages Survey Report in 2016. The report showed that median monthly salaries for employed Malaysian female were USD405.68 which is lower than employed Malaysian male with a median USD414.35 (24). Findings from a study in Portugal also discovered male-led household was protective against CHE in 2000. However, this study also highlights a shift in gender preference towards $\mathrm{CHE}$ in 2005 whereby male-led households were more prone to incur CHE. It is important to note that this study used $40 \%$ OOP health expenditure over non-food expenditure as an indication of $\mathrm{CHE}$, which meant the proportion of $\mathrm{CHE}$ was in fact, higher (25).

In Malaysia, the median salary in urban areas was higher compared with those employed in rural areas. In 2016, the median monthly salary among urbanites was USD481.52 compared to USD302.40 in a rural area. This explained the finding in this study where rural households were more likely to develop CHE. In this study, even though the urban population had higher OOP, but they were less likely to develop CHE than rural households. Furthermore, health insurance coverage may also play a role since $82.4 \%$ of those with health insurance were among the urban population which would give them more financial protection. Rural households are also more prone to CHE since they usually have to travel further to seek healthcare (mean distance $13.26 \mathrm{~km}$ ) compared to urban households (mean distance $9.18 \mathrm{~km}$ ) (4).

Household size of 1 to 2 person was found to be more at risk of developing CHE compared to households with 5 or more members. This was in line with findings in other countries such as Vietnam and Peru $(23,26)$. Two postulations may support this finding. First, in larger households, family members may provide better care to each other and encourage a healthier lifestyle thus reducing the utilisation of health services. Second, 
larger households especially those who are working can draw more resources and will share the financial burden during illness episode and at times of needs $(23,25,27,28)$.

Another factor that was found to be associated with the CHE in this study was the age of the head of household. Households with younger head of household ( $<60$ years old) was more likely to develop CHE compared to older household heads. A similar finding was also noted in Peru where head of household aged between 18-24 years old was more likely to incur CHE compared to head of household aged 45-54 years old (26). Although the mean OOP spending was higher among the head of household aged more than 60 years old, the multivariable analysis showed that head of household aged less than 60 years old were more prone to develop CHE. This was due to the significantly lower total expenditure among the younger head of households. Also, $75.2 \%$ of the low income group was from younger head of households which could have contributed to the occurrence of CHE.

\section{Study limitations}

Although this study used a large national household survey, there were limitations that can be improved in future studies. This study uses secondary data gathered from the $2015 / 2016$ HES published by the Department of Statistics, Malaysia. The variables that were collected in this survey were limited, and some of the important factors associated with CHE were not available from the survey. For example, in the literature review, factors such as type of illness and number of household members with disabilities were not available in the survey. Since this is a household population survey, respondents may be exposed to recall bias during the survey which may affect the accuracy and the quality of the data obtained. However despite these limitations, a household survey remains the best source of data in determining $\mathrm{CHE}$ of a country (1). In addition, respondents may fabricate their monthly income. This was apparent for those who worked in informal sectors without documented payslip. More accurate data on income, however, can be obtained through income tax records but this will not be made available to researchers. Since this is a cross-sectional study where both independent and dependent variables are being collected simultaneously, the cause and effect relationship cannot be determined.

\section{Conclusions}

The SDG 3.8.2 on the proportion of households with CHE among Malaysian households was $2.8 \%$. Four factors were significantly associated with $\mathrm{CHE}$ i.e. age and gender of household heads, household size and location. Despite the majority of Malaysians were financially protected from CHE, the number of households suffering from this situation is on an increasing trend. Undeniably, vulnerable groups among the Malaysian populations who suffered from CHE should not be overlooked as they require assistance to prevent further debt and the vicious cycle of illness and poverty. To determine a more accurate analysis of financial risk protection and health coverage, a more specific survey is required to identify vulnerable groups who suffer financial catastrophe from a specific disease. Since the proportion of CHE among Malaysian households is low in this study, the current health financing should be maintained. However, the increasing cost of healthcare makes it challenging for healthcare in Malaysia to remain financially sustainable. Malaysians, rich or poor, take advantage of the inexpensive healthcare services in public hospitals. Hospitals become crowded and health resources are stretched thin; thus jeopardising future access to care of the most vulnerable groups. A health financing policy in Malaysia is required to avoid abuse and to ensure these financial assistances are provided only to genuine CHE cases determined by the SDG 3.8.2 indicator.

\section{List Of Abbreviations}

WHO World Health Organisation

UHC Universal Health Coverage

SDG Sustainable Development Goals

HES Household Expenditure Survey

OOP Out-of-Pocket

CHE Catastrophic Health Expenditure

NHMS National Health and Morbidity Survey

MNHA Malaysia National Health Account

$\mathrm{MOH}$ Ministry of Health

WHOWPR World Health Organisation Western Pacific Region 
DOSM Department of Statistic Malaysia

ROC Receiver Operating Characteristic

OR Odd Ratio

AOR Adjusted Odd Ratio

Cl Confidence Interval

\section{Declarations}

\section{Ethics approval and consent to participate}

The study was conducted according to the principles outlined in the Declaration of Helsinki.Ethical approval was obtainedfrom the Human Research and Ethics Committee, UniversitiSains Malaysia USM/JEPeM/18100502 (Appendix 2) andCommittee from National Institute of Health, Ministry of Health Malaysia NMRR-18-3652-44558.

\section{Consent for publication}

Not applicable

\section{Availability of data and materials}

The data that support the findings of this study belonged to theDepartment of Statistics, Malaysia and is currently not available for public use. However,upon reasonable request,formal application to use the data may be submitted to the data custodian, Dr Shamsul Rijal Muhammad Sabri from the School of Mathematical Science, UniversitiSains Malaysia, Penang.

\section{Competing interests}

The authors declare that they have no competing interests

\section{Funding}

No funding was received for this study.

\section{Authors' contributions}

SS devised the main conceptual ideas, supervised the workprocess, draftedand submitted the manuscript. MS conducted the data collection, analysis and completed the report.

\section{Acknowledgements}

The authors would like to express appreciation to Shamsul Rijal Muhammad Sabri and the Department of Statistics, Malaysia for allowing the use of the Household Expenditure Survey 2015/2016 data.

\section{References}

1. World Health Organization. Tracking Universal Health Coverage: 2017 Global Monitoring Report. Switzerland: World Health Organization; 2017.

2. World Health Organization. Monitoring Universal Health Coverage and health in the Sustainable Development Goals: Baseline report for the Western Pacific Region 2017. Manila: World Health Organization Regional Office for the Western Pacific; 2017.

3. World Health Organization. Monitoring the building blocks of health systems: A handbook of indicators and their measurement strategies. Geneva: World Health Organization; 2010.

4. Institute of Public Health. 2015 National Health and Morbidity Survey. Institute for Public Health Malaysia; 2015.

5. Malaysia National Health Accounts. Malaysia National Health Accounts: Health Expenditure Report 1997-2018. Malaysia: Ministry of Health Malaysia; 2019.

6. Loganathan T, Lee WS, Lee KF, Jit M, Ng CW. Household catastrophic healthcare expenditure and impoverishment due to rotavirus gastroenteritis requiring hospitalization in Malaysia. PloS One. 2015;10(5):e0125878.

7. Wagstaff A, Flores G, Hsu J, et al. Progress on catastrophic health spending in 133 countries: a retrospective observational study. The Lancet Global Health. 2018;6(2):e169-e79. 
8. Van Doorslaer E, O'Donnell O, Rannan-Eliya RP, et al. Effect of payments for health care on poverty estimates in 11 countries in Asia: An analysis of household survey data. The Lancet. 2006;368(9544):1357-64.

9. Aregbeshola BS, Khan SM. Out-of-pocket payments, catastrophic health expenditure and poverty among households in Nigeria 2010. International Journal of Health Policy Management. 2018;7(9):798.

10. Ng CW. Universal Health Coverage Assessment Malaysia 2015 [Cited. Available from: http://gnhe.org/blog/wpcontent/uploads/2015/05/GNHE-UHC-assessment_Malaysia-1.pdf.

11. World Health Organization. UHC and SDG Country Profile 2018: Malaysia. Manila: World Health Organization Regional Office for the Western Pacific; 2018.

12. McIntyre D, McKee M, Balabanova D, Atim C, Reddy KS, Patcharanarumol W. Open letter on the SDGs: a robust measure for universal health coverage is essential. The Lancet. 2016;388(10062):2871-2.

13. Department of Statistic Malaysia. Report on Household Expenditure Survey 2016 Malaysia2017 [Cited. Available from: https://www.dosm.gov.my/v1/index.php? $r=$ column/cthemeByCat\&cat=323\&bul_id=WnZvZWNVeDYxKzJjZ3RIUVVYU2s2Zz09\&menu_id=amVoWU54UTI0a21NWmdhMjFMMWcyZz09.

14. Abd Mutalib NS, Soh YC, Wong TW, et al. Online narratives about medical tourism in Malaysia and Thailand: a qualitative content analysis. Journal of Travel Tourism Marketing. 2017;34(6):821-32.

15. Van Doorslaer E, O'donnell O, Rannan-Eliya RP, et al. Catastrophic payments for health care in Asia. Health Econ. 2007;16(11):1159-84.

16. Cylus J, Thomson S, Evetovits T. Catastrophic health spending in Europe: equity and policy implications of different calculation methods. Bull World Health Organ. 2018;96(9):599.

17. Azzani M, Yahya A, Roslani AC, Su TT. Catastrophic health expenditure among colorectal cancer patients and families: a case of Malaysia. Asia Pacific Journal of Public Health. 2017;29(6):485-94.

18. Sukeri S, Mirzaei M, Jan S. Does tax-based health financing offer protection from financial catastrophe? Findings from a household economic impact survey of ischaemic heart disease in Malaysia. International Health. 2017;9(1):29-35.

19. Yusof SA, Duasa J. Consumption patterns and income elasticities in Malaysia. Malaysian Journal of Economic Studies. 2010;47(2):91-106.

20. Pandey KR, Yang F, Cagney KA, Smieliauskas F, Meltzer DO, Ruhnke GW. The impact of marital status on health care utilization among Medicare beneficiaries. Medicine. 2019;98(12):e14871.

21. Rannan-Eliya RP, Anuranga C, Manual A, et al. Improving health care coverage, equity, and financial protection through a hybrid system: Malaysia's experience. Health Aff. 2016;35(5):838-46.

22. Sinha RK, Chatterjee K, Nair N, Tripathy PK. Determinants of out-of-pocket and catastrophic health expenditure: a cross-sectional study. British Journal of Medicine Medical Research. 2016;11(8):1.

23. Van Minh H, Phuong NTK, Saksena P, James CD, Xu K. Financial burden of household out-of pocket health expenditure in Viet Nam: findings from the National Living Standard Survey 2002-2010. Soc Sci Med. 2013;96:258-63.

24. Department of Statistic Malaysia. 2016 Salaries and Wages Survey Report Malaysia. 2017.

25. Kronenberg C, Barros PP. Catastrophic healthcare expenditure-drivers and protection: the Portuguese case. Health Policy. 2014;115(1):44-51.

26. Falconi DP, Bernabé E. Determinants of catastrophic healthcare expenditure in Peru. International Journal of Health Economics Management. 2018;18(4):425-36.

27. Zhou Z, Gao J. Study of catastrophic health expenditure in China's basic health insurance. HealthMED. 2011;5:1498-507.

28. Li Y, Wu Q, Xu L, et al. Factors affecting catastrophic health expenditure and impoverishment from medical expenses in China: policy implications of universal health insurance. Bull World Health Organ. 2012;90:664-71. 